\title{
A ressignificação do têxtil: como usar resíduos têxteis na criação de produtos sustentáveis através do design
}

Joelma Pacheco Lopes;

Clara Santana Lins Cerqueira

\section{resumo:}

A pesquisa foi desenvolvida com o intuito de entender a importância da indústria têxtil no mundo e no Brasil, sobre problemas acarretados que a mesma gera e como o design pode oferecer soluções sustentáveis a partir desse contexto. A ideia central do projeto é a aplicação do design na reutilização de retalhos descartados pelas confecções, de médio e grande porte, a fim de desenvolver um produto que atendesse ao pensamento sustentável. Portanto, a pesquisadora teve como pesquisa de campo uma empresa de confecção de uniformes, situada na região da cidade de Ubá, para desenvolver estratégias de reaproveitando dos retalhos descartados pela confecção e futuramente elaborar um produto, através de métodos e ferramentas de design, que ressignifique o valor do tecido descartado no mercado vigente. Para isso, foi feito também um estudo da Geração $Y$, identificado na pesquisa como o público de maior interesse no tema abordado pelo presente projeto.

palavras-chave:

design sustentável; têxtil; ressignificação 


\section{Introdução}

As indústrias de confecção no Brasil têm quase 200 anos e, segundo a Associação Brasileira da Indústria Têxtil e de Confecção (ABIT, 2017), é a $2^{\mathrm{a}}$ maior geradora de empregos no país, atrás somente dos alimentos e bebidas juntos, representa $16,7 \%$ dos empregos e $5,7 \%$ do faturamento da indústria de transformação. No país existem 27,5 mil empresas formais ligadas ao ramo têxtil, com produção média de 8,9 bilhões de peças, ou seja, 1,3 milhão de toneladas em média de produção têxtil. Além do mais, a moda brasileira está entre as maiores das Semanas de Moda no mundo.

Segundo a ABIT, se calcula uma perda de $10 \%$ de tecido no processo de corte para confecção, e destes, $60 \%$ que somam aproximadamente 100 toneladas, são resíduos têxteis que tem como destino os aterros ou lixões, que já estão comprometidos pela quantidade de resíduos sólidos à eles enviados.

Hoje, a sustentabilidade já é considerada regra na maioria das empresas, e a sociedade está atenta quanto a isso, o Instituto Brasileiro de Defesa da Natureza (IBDN) aponta o Brasil como o país com mais consumidores preocupados com a preservação ambiental e a sustentabilidade.

Nesse contexto, essa pesquisa tem o intuito de desenvolver um puff com sua estrutura de ferro, que possa utilizar ao máximo desses resíduos, que em sua maioria são retalhos ainda com prospecção de uso, mas que são ignorados pelas grandes indústrias. Portanto, a pesquisa teve como foco o público da Geração Y, que além de ambientalmente consciente, são jovens dispostos a investirem tempo e dinheiro em atitudes e hábitos que apresentem à novas experiências e conquistas.

O presente artigo aborda inicialmente o consumo por trás da indústria têxtil e seus impactos na sociedade, bem como abordar o papel do design nesse setor. O trabalho também deixa em evidência a necessidade do design emocional para conseguir atingir e conquistar o usuário. Assim, o trabalho se baseia em alguns exemplos de processos de upcycling e slow movement para a ressignificação e efetiva valorização do material dos tecidos descartados.

\section{A cultura de consumo de tecidos e o papel do design sustentável na atualidade}

Ruthschilling (2008) em sua obra "Design de Superfície", disserta que por volta de 10.000 a 5.000 anos a.C. no período Neolítico, inicia-se a fiação, a qual é a utilização de fibras para fabricação de fios, e também a tecelagem, que por sua vez, é o conjunto de técnicas de entrelaçamento de fios para confecção dos tecidos. Considera-se a tecelagem uma tecnologia fundamental na cultura humana, seu conhecimento construído foi cumulativo, um exemplo disso são as suas estruturas têxteis básicas, que permanecem ainda inalteradas nos sistemas produtivos. Assim, há muito tempo o tecido faz parte da cultura material e da construção sociocultural da sociedade.

$\mathrm{Na}$ contemporaneidade e no capitalismo imodesto como aponta Lipovetsky e Serroy (2015), ressaltam que com a popularização das lojas de departamentos, em que foi empregado o poder emocional do sentimento estético, se democratizou os artigos ali encontrados, com preços mais acessíveis, o que antes era disponível apenas à elite. A indústria e as lojas de departamento passam a reforçar a necessidade desenfreada de comprar e consumir como um novo estilo de vida.

Sudjic (2010) discorre que a moda a partir da sua transformação de artesanato para indústria, apresenta consequências que transcende a própria indústria. Moldando e influenciando todas as outras, estendendo seu processo de fazer moda e como resultado os demais produtos desenvolvem características obsoletas. Porém, como a moda se tornou o promotor da mudança cultural, Sudjic explica que "fazer ou usar moda toca diretamente quase todo mundo. A moda reflete a natureza de grupos ou indivíduos autodefinidos, e a moral e a fé que compartilham. Mas também tem sido a força motriz por trás da industrialização."

Portanto, a procura por novidades se tornou um costume estabelecido entre os indivíduos e a sociedade de maneira geral. De forma lenta e pontual, contudo, é possível ver pequenas manifestações que fomentam outra perspectiva do consumo como o conhecemos e, assim, os resultados ainda não são e provavelmente não serão suficientes para substituir imediatamente o consumo voraz por um consumo mais consciente.

O início desse pensamento surge em 1972, na Conferência das Nações Unidas sobre o Ambiente Humano sediada em Estocolmo na Suécia, que teve com o intuito de debater sobre poluição atmosférica que já preocupava a comunidade científica. Os assuntos debatidos foram acerca a poluição 
da água e a do solo provenientes da industrialização e a pressão do alto crescimento demográfico sobre os recursos naturais (RIBEIRO, 2001).

Wanderley et al.(2013), dissertam que os designers compactuados com a causa na época, repensaram o sistema econômico e político da época e sugeriram estilos de vida alternativos, abrindo espaço para projetos que incentivam o "faça você mesmo". A autora disserta que outros pesquisadores como Victor Papanek, por exemplo, discutiram sobre a natureza social do trabalho do design, no chamado designer do "mundo real". Portanto, engendrou-se um debate sobre o envolvimento do design e tecnologia, questionando o progresso e desenvolvimento em cima do consumo exacerbado, colocando em pauta o pensar ecológico e a proteção dos recursos naturais e ambientais (WANDERLEY et al., 2013).

Segundo Cardoso (2008), surgiu na década de 1980, principalmente na Europa e América do Norte, um novo tipo de consumidor disposto a pagar mais caro por produtos ecologicamente corretos, desenvolvendo-se, assim, produtos e embalagens sustentáveis, estratégias e propaganda para atrair esses consumidores. Portanto, criou-se uma gama de oportunidades para os designers.

$\mathrm{O}$ design se encontra em todas as fases do desenvolvimento de um produto, ou seja, pesquisa, produção, distribuição e descarte. De acordo com Silva (2010), o design é como parte da solução, um elemento capaz de auxiliar no desenvolvimento de alternativas racionais, fomentando, assim, uma sociedade mais sustentável. Para ele, o designer com consciência ambiental, e através de seus métodos, é capaz de criar caminhos que sensibilizem as pessoas a se interessarem pelas causas sustentáveis.

Todavia, Manzini e Vezzoli (2008) deixam claro que, a sustentabilidade é um objetivo e não um meio, como muitas vezes é interpretado, ou seja, dispor de pequenas melhorias em temas ambientais, não pode ser posto como algo sustentável.

Com a industrialização, o consumo passou a ser parte da economia de forma direta, e com isso, à medida que se consome, mais produtos são descartados e encaminhados para o lixão. Para Lipovetsky e Serroy (2015), a indústria da moda é uma das mais responsáveis por essa prática efêmera, e apesar da vida útil dos industrializados serem cada vez menor, o design tem evoluído cada vez mais rápido no planejamento de produtos e na resolução de problemas.

Através do viés sustentável, muitas empresas têm se apoiado em novas opções de processos para assim reduzir os problemas ambientais. Uma dessas soluções é o upcycling, que aproveita de materiais descartados para transforma-los em novos produtos, sem utilizar de processo químico, mas mantendo a alta qualidade dos mesmos. Reduzindo, assim, a necessidade de novas matérias-primas na fabricação de novos produtos (LUCIETTI et al., 2018). Outro exemplo interessante é o Slow Movement [movimento lento] tem o intuito de despertar a consciência e a responsabilidade do descarte final de produtos, proporcionando maior entendimento para o consumidor dos impactos da cadeia produtiva, desde a extração dos substratos até o fim da vida do produto. Portanto, o movimento afeta positivamente a forma que as pessoas consomem e se relacionam com a natureza. A preocupação com o meio ambiente e o aquecimento da produção local, geram a diferenciação no resultado.

Portanto, diversos empreendimentos com práticas sustentáveis surgem para $o$ reaproveitamento de matérias primas descartadas gerando negócios locais para repensar o descarte efêmero das mesmas. Exemplo disso, é a empresa Banco de Tecido, fundada pela cenógrafa Luciana Bueno, que teve a ideia de fazer uma espécie de troca entre amigos e profissionais interessados nesses tecidos, como um estoque coletivo (MIZUTA, 2016).

$\mathrm{Na}$ pesquisa e no projeto prático aqui proposto, por exemplo, é utilizado os retalhos têxteis para revestir um puff com estrutura de ferro, sem a necessidade de desfibragem ou qualquer tipo de processamento. Somente com a utilização de nós e entrelaçamento dos tecidos, essa finalização do produto é feita de forma manual e artesanal. Intenciona, portanto, criar um diálogo sobre o design enquanto ferramenta que desafia o conceito formal de estética, ressignificando e desconstruindo padrões, e fomentar um consumo por valores intangíveis ligados à sustentabilidade do produto e seu valor emocional, como fazem, por exemplo, os designers e arquitetos Irmãos Campana.

\subsection{A ressignificação do têxtil em produtos: como inovar no design sustentável}

$\mathrm{O}$ design vai muito além criar novos produtos. Este perpassa por fatores que envolvem a estética, o funcionalismo dos artefatos e o valor utilitário que os mesmos devem possuir. Contudo, segundo 
Sudjic (2010), design também é linguagem, pois esses bens de consumo passam a tangibilizar cultura, valores, anseios e desejos dos seus consumidores. O objeto passa a contar uma história, e a transmitir significados e significância que despertam para o verdadeiro valor do papel do designer enquanto profissional na sociedade vigente.

Os objetos são nossa maneira de medir a passagem de nossas vidas. São o que usamos para nos definir, para sinalizar quem somos, e o que não somos. Ora são as joias que assume esse papel, ora são os móveis que usamos em nossas casas, ou os objetos pessoais que carregamos conosco, ou as roupas que usamos.

E o design passou a ser linguagem com que se molda esses objetos e confecciona as mensagens que eles carregam. O papel dos designers mais sofisticados, hoje, tanto é ser contadores de histórias, fazer um design que fale de uma forma que transmita essas mensagens, quanto resolver problemas formais e funcionais. Os designers manipulam essa linguagem com mais ou menos habilidade ou encanto, para transmitir o tipo de história que meu Mackbook cochichou no meu ouvido em Heathrow (SUDJIC, 2010)

O autor disserta sobre a relação física e ao mesmo tempo abstrata - como, por exemplo, a identidade assumida pelos indivíduos - do homem com os objetos, e como eles definem trechos da história e das vidas particulares do mesmo.

O design se insere na lógica do consumo como um mediador entre usuário e produto, afim de que os mesmos se percebam no espaço, estimulando até mesmo um sentimento afetivo, como a relação do autor que se se encantou por um Mackbook.

Norman (2008), em sua obra "Design Emocional", explica sobre as relações interpessoais do usuário e produto como um processo dividido em três bases cognitivas, que se relacionam intrinsecamente com as emoções do sujeito. São elas: viscerais, comportamentais e reflexivas. Quando o homem lida com uma situação, ele é capaz de refletir sobre sua experiência para que futuramente possa tomar uma decisão melhor. Através do pensamento consciente, o entendimento de novos conceitos e generalizações a respeito do mundo se torna mais plausível.

A lógica do consumo se baseia cada vez mais na abstração dos produtos, pautando-se no valor simbólico que os mesmos apresentam, ou sobre a ideia que querem transmitir, ou ainda, a experiência que intencionam promover.

Por isso, um dos principais temas que mais fazem parte dos debates atuais são aqueles que envolvem a preocupação com os recursos naturais, a escassez dos mesmos, bem como soluções ecológicas. Papaneck em 1971, em sua obra "Design para o mundo real", já despertava para a consciência do designer frente aos temas de sustentabilidade e o papel imprescindível do profissional de se projetar para um mundo com uma situação real de finitude dos recursos naturais disponíveis para as futuras gerações.

Portanto, é relevante refletir como o design pode repensar produtos e insumos descartados por indústrias e consumidores, ressignificando, assim, o valor dos mesmos para a conversão de um pensamento mais sustentável e medidas mais ecológicas acerca do planejamento dos processos de produção e fabricação. Nesse contexto, a indústria têxtil tem uma percentagem assustadora no que tange ao descarte de tecidos, segundo Luiza Lorenzetti (2018), representante da ABIT, cerca de 170 mil toneladas de resíduos têxteis são produzidas por ano, e apenas $40 \%$ passam por empresas recicladoras através da logística reversa.

A indústria da moda é considerada atualmente como a terceira atividade econômica em termos de geração de renda e movimentações financeiras. Porém, grande parte de seus produtos geram, de alguma forma, degradações no ambiente durante todo o processo do produto (LUCIETTI et al., 2018).

Uma iniciativa crescente no processo de recuperação é o upcycling, que utiliza materiais que já seriam descartados, transformando-os em novos produtos com melhor qualidade e valor ecológico, sem passar por qualquer tipo de processo químico. Outra vertente em alta na sociedade contemporânea que aborda o tema é o grande número de adeptos do movimento slow fashion, que sugere uma consciência tanto no lado da oferta quanto do cliente, ou seja, é uma tendência para a desaceleração do tempo de produção e consumo (LUCIETTI et al., 2018).

Portanto, ressignificar produtos se trata de dar novos sentidos aos mesmos, gerando novos valores e consequentemente, novas experiências. Assim, para o design, quando se ressignifica 
elementos, símbolos, atributos e no uso dos objetos, da cultura material, se altera também o contexto e sua interpretação.

E como Sudjic (2010) declara, "o design é um reflexo de nossos sistemas econômicos." E para ele ter uma linguagem que atue e reflita nos valores emocionais, é importante que o produto tenha um significado e uma presença forte no ambiente do qual será inserido. Aplicar retalhos têxteis de forma não convencional em mobiliários bastantes comuns nas residências atualmente, e de uma maneira em que a fabricação e montagem sejam até simples de executar, mostra que as pessoas almejam cada vez mais por soluções sustentáveis.

O planejamento sustentável de novos produtos se faz imprescindível na sociedade vigente. Nesse contexto, é posto nos seguintes tópicos, designers conceituados e a relação deles com os materiais reaproveitados, a nova forma de se usar e repensar simples objetos. Assim, trazer a luz, como alguns projetos e atitudes influencia na percepção e no impacto gerado a partir de materiais comuns sob uma nova perspectiva.

Humberto e Fernando Campana não são designers por formação, mas sim profissionais de design, e suas influências não deixam a desejar. São conhecidos por transformar o banal em "falsos diamantes", reutilizando materiais e utensílios encontrados no cotidiano para criar obras de arte, estas espalhadas em museus no mundo inteiro principalmente no MoMa em Nova York. O diferencial dos Campana é sua essência na cultura brasileira, preferindo materiais e técnicas mais simples, refletindo principalmente questões do cotidiano.

Uma de suas criações é a poltrona "banquete" com estrutura em aço inox e diversos bichos de pelúcia formando o assento. Quando é alterada a função do brinquedo, altera também o olhar do espectador diante do resultado. $\mathrm{O}$ produto transcende a função primária e passa a dialogar emocionalmente com o usuário. $\mathrm{O}$ produto tende a encantar o consumidor transmitindo com uma mensagem subjetiva para cada um.

Designer carioca, Brunno Jahara estudou desenho industrial na Universidade de Brasília, mudou para Itália, se formou na Universidade de Arquitetura de Veneza e começou sua carreira na Espanha. Seus produtos possuem identidade brasileira, mas sempre comunicando internacionalmente. Em seu estúdio são criadas obras de arte unindo inovação e artesanato, com peças únicas. Cada uma contando uma história através processo de fabricação.

Mesclando dois materiais distintos e opostos como o latão maciço, nobre e resistente e a palha, modesta e flexível, nas mãos do designer Brunno Jahara e da estilista Ana Voss, a palha ganha vida e importância nessa coleção (Figura 2). Ao alterar seu contexto de produção e técnica , a palha se mostra versátil e transpõe outros significados na valorização de uma cultura e de suas tradições. Assim, o artesanato passa a ganhar valor no projeto de produtos e na decoração.

\section{Estudo de caso: reaproveitamento do retalho de tecidos em uma empresa de confecção na cidade de Ubá}

Localizada na região sudeste do estado de Minas Geais, mais especificadamente na Zona da Mata, Ubá possui, segundo o último censo do Instituto Brasileiro de Geografia e Estatística (IBGE), 101.519 habitantes. Seu produto interno bruto (PIB) per capita é de R\$22.023,63 (IBGE, 2016). É conhecida nacionalmente como um dos principais polos moveleiros do Brasil (INTERSIND, 2019), mas a cidade também abriga um número significativo de confecções representando a indústria têxtil na região, a qual apresentam uma produção variada, incluindo lingerie, enxovais, uniformes e principalmente jeans. Assim, a indústria têxtil foi escolhida como foco do presente trabalho.

Portanto, na presente pesquisa, foi escolhida uma indústria têxtil referência em confecção de uniformes na região de Ubá, localizada no bairro Santana para pesquisa de campo e coleta de dados. A empresa trabalha com alguns tipos de tecido, alguns destes, por exemplo, é o jeans, brim, moletom, tactel, linha social e malharia. Da quantidade de tecidos usados, $15 \mathrm{~kg}$ aproximadamente se transformam em retalhos semanalmente. O descarte dessas sobras é feito de 3 maneiras. A primeira é repassando-os para oficinas mecânicas para limpeza de peças automotivas, e também para a estamparia terceirizada para manutenção e limpeza das matrizes; a segunda, as sobras são doadas para uma artesã que produz artesanatos; e o restante é separado para o lixo comum. 


\subsection{Metodologia}

Baxter (2011) cita três regras fundamentais de um projeto de design: estabelecer metas, acompanhar o processo e ser criativo. Com isso em mente, a pesquisadora montou sua própria metodologia, ilustrada na Figura 1, baseia-se nas ferramentas de design de Mike Baxter, nos processos de Bruno Munari e nos métodos para design de produtos de Ana Veronica Pazmino. Sua metodologia se resume em três etapas, as quais são cíclicas, podendo assim, retornar sempre que necessário na etapa anterior para verificação e correção, como se pode observar na imagem a seguir.

Figura 1 - Metodologia Criativa.

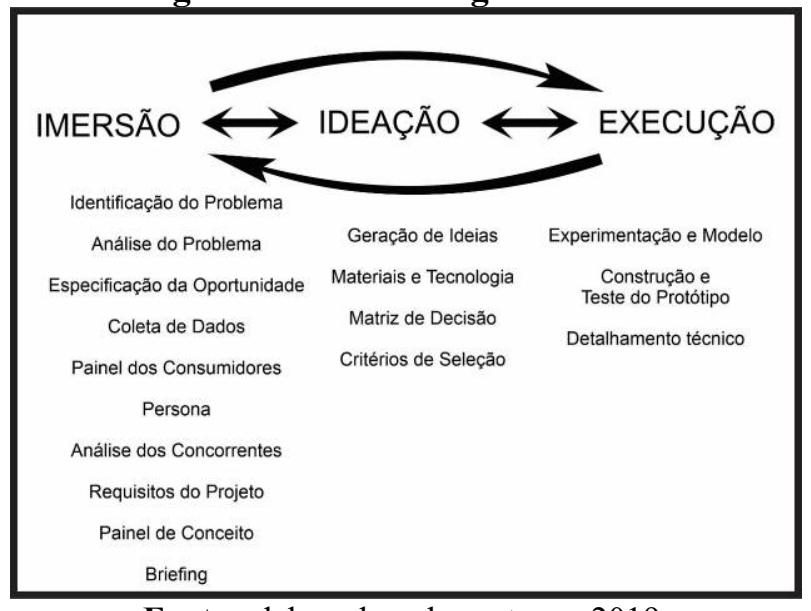

Fonte: elaborado pelas autoras, 2019.

$\mathrm{Na}$ etapa de Imersão, a fase que deve tomar mais tempo do projeto, contém: a "identificação do problema", a qual seria a definição de um problema identificado. Em seguida faz-se a análise deste problema para entender suas causas principais e certificar se há um incômodo do qual necessita de solução. O próximo passo é caracterizado por especificar a oportunidade, onde é detalhada a exigência do mercado para a concepção de um novo produto.

Feito isto, realiza-se uma extensa coleta de dados, a contextualização histórica do assunto, por exemplo, o que a mídia diz sobre, se existe e como as pessoas lidam com esse problema, quem são os interessados e consumidores, possíveis concorrentes diretos e indiretos. Após realizada a pesquisa e conhecendo bem o público alvo, monta-se um painel que consiga traduzir o perfil do usuário, favorecendo o reconhecimento do público de interesse, a partir de aspectos como cor, materiais, característica formal ou tecnológica do estilo de vida do consumidor. Em seguida, é montada a persona na busca de descrever de forma mais eficiente o público alvo. $\mathrm{Na}$ análise dos concorrentes é feita a identificação dos pontos fortes e fracos das soluções geradas pelos concorrentes, sejam eles diretos ou indiretos, ajudando assim a melhor planejar a estratégia da solução.

Os requisitos do projeto são o registro das necessidades e metas para com o público alvo, transformando-se em um guia para o controle de qualidade do desenvolvimento do projeto juntamente com o painel de conceito, pois esse ajuda na visualização e interpretação das características do projeto, facilitando as gerações de alternativas. E, finalizando a primeira etapa, a construção do briefing com o resumo de todas as informações relevantes, como necessidades e restrições, estruturadas de forma a auxiliar na verificação em todo o desenvolvimento projetual.

A etapa de Ideação engloba: a geração de ideias, onde o mais apropriado é anotar ou desenhar todo tipo de insight que norteie para a solução final. Simultaneamente ou não, o designer precisa buscar dados sobre materiais e tecnologias ou técnicas de fabricação que compactue com o desenvolvimento do projeto. A Matriz de Decisão é uma ferramenta para ajudar na escolha da melhor alternativa dentre as várias propostas na fase de geração de ideias, estabelecendo critérios capazes de medir se a solução atende os requisitos previamente estabelecidos. Acompanhando a Matriz de Decisão, é necessário montar um "funil" para avaliar de forma mais criteriosa os aspectos 
quantitativos e qualitativos adaptados ao projeto, utilizando um checklist, para que se marque ao lado se a alternativa atende ou não a determinado critério constatado no briefing $^{I}$.

$\mathrm{Na}$ execução, terceira e última etapa da presente metodologia, o designer deve experimentar os materiais e técnicas disponíveis para o projeto, confeccionando modelos em escala ou tamanho real, descobrindo assim novas possibilidades de aplicações do material ou instrumento. A construção de um protótipo no material e escala proposto em uma fase inicial, pode ser muito custosa para o projeto, mas à medida que ele se desenvolve, os riscos de falhas tendem a diminuir, portanto, o custo do teste no protótipo final pode ter um bom retorno, antecipando o aparecimento de possíveis falhas funcionais e estratégicas antes do produto chegar ao mercado. Por fim, é feito o detalhamento técnico para representar o projeto de forma mais precisa, permitindo assim que seja replicado futuramente de maneira mais ágil, não demandando a necessidade de refazer o projeto inteiro.

\subsection{Identificação do público alvo}

Através de pesquisas bibliográficas e documentais que explorassem as diversas gerações, bem como as práticas de consumo ligadas a elas, foi percebido que a geração Millennials, com enfoque na faixa etária de 19 a 29 anos, se enquadra nos aspectos pretendidos da pesquisa. A Geração Y ou Millennials é geralmente definida pelos pesquisadores como 80 milhões de pessoas nascidas entre 1980 e 2000 (RIBEIRO et al., 2017). Segundo Virgílio (2017), esse público se caracteriza por estar sempre buscando novos produtos e serviços e sentem a obrigação de fazer mais pela sustentabilidade. Assim, em nossa contemporaneidade, é um público de peso com requisitos e demandas específicas e diversas.

Esse público está sempre buscando novos produtos e serviços e sentem a obrigação de fazer mais pela sustentabilidade. $\mathrm{O}$ desejo da casa e carro próprio, por exemplo, se tornou algo para posteridade. Com a facilidade de acesso à tecnologia, preocupação com a sustentabilidade, e por uma questão de custo-benefício, os Millennials preferem o compartilhamento do carro (VIRGÍLIO, 2017).

Os que nasceram no início da Geração já tinham uma visão de mundo formada, vivendo parte da vida sem internet, tendendo a serem mais otimistas, colaboradores e flexíveis, pois tinham que se readaptar ao mundo depois da recessão econômica. Ao contrário dos que nasceram da metade para o final da Geração Y, que tiveram a recessão como base para sua formação e foram crianças e adolescentes já com acesso à internet, a tendo como parte fundamental de sua vida, tendendo a serem mais objetivos, financeiramente conscientes e questionadores (DEARO, 2017).

Dessa forma, para essa pesquisa, como foi dito, foi definido os New Millennials, um público busca produtos de qualidade e que o conquiste intrinsecamente, sendo adequado a escolha dos New Millennials para este projeto, especialmente por se tratar de um trabalho buscando alternativas sustentáveis para a reutilização de retalhos têxteis.

\subsection{Briefing}

Também conhecido como Briefing de Projeto, é um documento que deve conter todas as informações para o planejamento e execução do projeto. Segundo Phillips (2007), o briefing atua como roteiro a ser seguido durante o decorrer do mesmo, englobando informações específicas e estratégicas, delimitando as etapas intermediárias, elaborando o cronograma e definindo o orçamento para cada etapa.

Portanto, é importante que o designer entenda a relevância de iniciar um projeto a partir das informações fornecidas pelo cliente para, assim, projetar de maneira contundente e eficaz através dos métodos e processos estabelecidos para seu o desenvolvimento.

\subsection{Identificação do público alvo}

A ferramenta "Persona" é comumente utilizada no processo criativo de design para observar os comportamentos e desejos do público alvo escolhido. Essas pessoas imaginárias, fictício ou não, são construídas a partir do estudo de mercado, pesquisas, entrevistas e questionários. Segundo Pazmino (2015), quando o designer aplica a persona em seu projeto, se tem uma nova perspectiva para o público, resultando em um relacionamento mais humano e afetivo entre o criador e o usuário, possibilitando que o projeto se torne mais assertivo e tenha um bom feedback do mercado.

\footnotetext{
${ }^{1}$ Segundo Phillips (2007), o briefing atua como roteiro a ser seguido durante o decorrer do mesmo, englobando informações específicas e estratégicas, delimitando as etapas intermediárias, elaborando o cronograma e definindo o orçamento para cada etapa.
} 
Para essa pesquisa foi elaborado, portanto, três personas para representar e expressar mais claramente esse público, seus anseios e desejos.

Percebe-se, independente da idade das personas, eles almejam de alguma forma seu bem-estar e independência pessoal. Precisam da internet e conectividade em seu dia a dia, e estão em busca de uma maneira de crescer financeiramente. Há momentos em que eles preferem passar a maior parte de seu tempo em casa desfrutando do conforto do lar, e outros em que irão preferir sair e conhecer as experiências que o mundo tem a oferecer.

\subsection{Definindo o produto}

Com base no comportamento da idade geracional do público, e mediante a demanda do mercado por produtos mais sustentáveis, foi definido que o produto a ser desenvolvido para este projeto, seja um mobiliário que tenha em sua estrutura retalhos descartados da indústria têxtil. É, pois, importante que tenha como atrativo principal seu aspecto decorativo, emocional e também conceitual. Independente do usuário morar com os pais ou já ter sua própria casa, ele desejará o produto por esse refletir seus ideais e também seu estilo de vida.

Assim, O produto estabelecido foi um puff, referenciando a jovialidade da geração além de ser capaz de propiciar a inserção dos retalhos de confecções sem perder a espontaneidade e versatilidade do produto. Os puffs são assentos baixos sem apoio para as costas ou braços que podem ser colocados em qualquer ambiente da casa, principalmente quarto, sala ou escritório. Por serem móveis versáteis e admitirem variados materiais tanto em sua estrutura como em seu acabamento, a procura por esse produto no mercado vem crescendo cada dia mais. Os modelos mais descontraídos e divertidos chamam a atenção dos jovens e é uma excelente opção na composição e decoração do ambiente sem perder o conforto que é algo primordial quando se quer sentar e ter uma conversa informal.

\subsection{Painéis}

Através das pesquisas e análise do público Millennials feitas no capítulo 5.1.1 "Identificação do público alvo", foram observados padrões de consumo, hábitos e vivências que descrevem o público alvo. Dessa forma, foi utilizada a ferramenta de painéis que, segundo Pazmino (2015), atuam como meio de comunicação capazes de traçar o perfil do público, utilizando de imagens que permitam que o designer visualize de forma clara os aspectos subjetivos da vida do consumidor ou usuário.

\subsubsection{Identificação do público alvo}

Os Millennials são pessoas conectadas e a tecnologia é como se fosse uma extensão de seus corpos. O perfil do público alvo desse projeto, é aquele que gosta de compartilhar cada momento de sua vida, se importa com momentos de lazer com seus amigos e família, gostam de ter sua saúde em dia e dedicam tempo para isso. Para eles, o meio ambiente e o futuro estão intrinsecamente ligados, apoiam projetos e iniciativas que valorizam a sustentabilidade do planeta. Assim, as imagens na Figura 2 definem, na visão da pesquisadora e designer, o estilo de vida que esse público consome e vive.

Figura 2 - Painel identificação do público alvo.

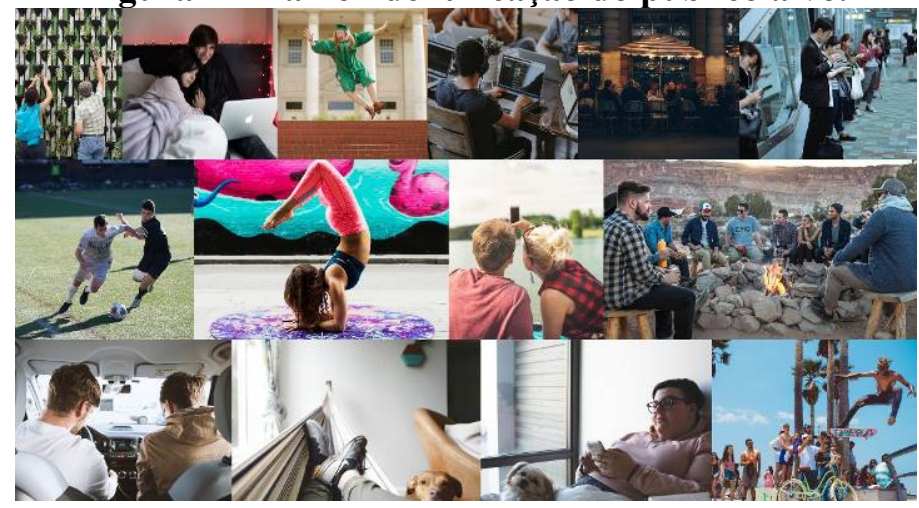

Fonte: UNSPLASH, 2019. 


\subsubsection{Painel Semântico}

Foram desde muitos novos introduzidos ao mundo virtual, possibilitando a conexão e vivência com outras culturas. São pessoas de "espírito livre", com consciência dos problemas do mundo e apoiam a igualdade de gênero, por exemplo. Estão sempre à procura de novas experiências de consumo, não se importando com os produtos em si. São generosos e sempre dispostos a ajudar o próximo, visando também as próximas gerações. Portanto, o painel apresentado, na Figura 3, tem a intenção de demonstrar as sensações, emoções e sentimentos que definem o público em questão.

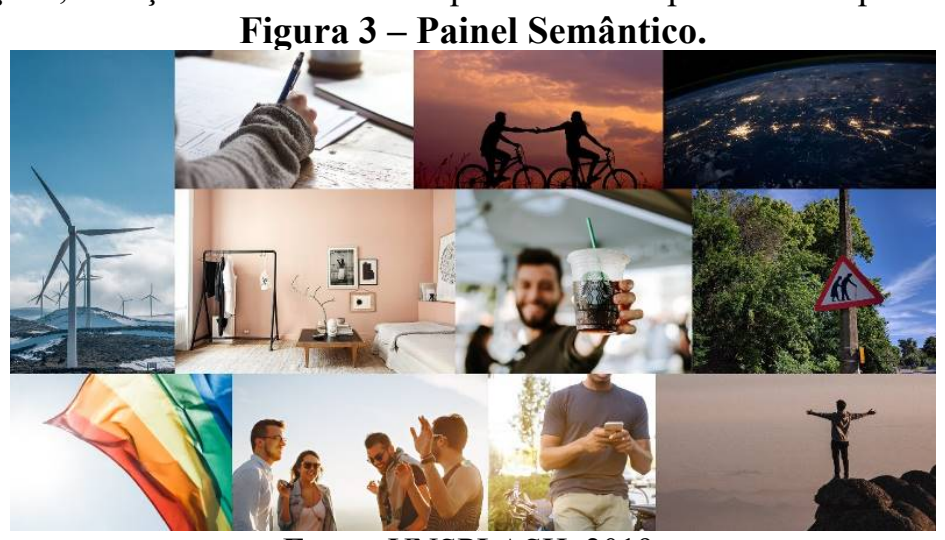

Fonte: UNSPLASH, 2019.

\subsubsection{Inspiração e Conceito}

Em busca de possíveis soluções para o projeto, a autora procurou se inspirar na natureza, técnica chamada de biomimética ou biônica, que segundo Detanico et al. (2010) são abordagens tecnologicamente baseadas na natureza através de observações e análises dos princípios de funcionamento para assim aplicar no design e solucionar os problemas do homem, ou seja, os estudos nessa área são fundamentados nas soluções naturais, adaptando desse modo formas e funções, na busca do melhor aproveitamento e menor gasto de energia.

A partir disso, o projeto teve como inspiração, através de um insight, os pássaros, mais especificamente os conhecidos como caramancheiro ou pavilhão, que constroem uma estrutura semelhante a um pergolado e decoram com gravetos e objetos de cores vivas no esforço de atrair e conquistar sua parceira fêmea, principalmente durante seu período reprodutivo (G1, 2012). Em algumas espécies, como parte desse ritual de conquista, o macho sai à procura por objetos para construir e se avistarem algo colorido, independente se for lixo ou não, o pássaro leva para decorar seu ninho e agradar sua fêmea.

Com o objetivo de auxiliar na fase criativa, o painel de inspiração serve para concentrar o imaginário em volta do que se almeja alcançar, composto de itens que ajudem no desenvolvimento e nas gerações de alternativas. E como o foco do projeto é ressignificar e trazer novas funções para o descarte de retalhos de confecções, o pássaro foi utilizado como inspiração e conceito para auxiliar a etapa de solução projetual.

O painel a seguir (Figura 4) é formado por imagens de uma das espécies de caramancheiro, e ilustra como ele adapta os objetos muitas vezes descartado por humanos e os reutiliza decorando os ninhos e estruturas para a conquista da fêmea.

Figura 4 - Painel Inspiração e Conceito.

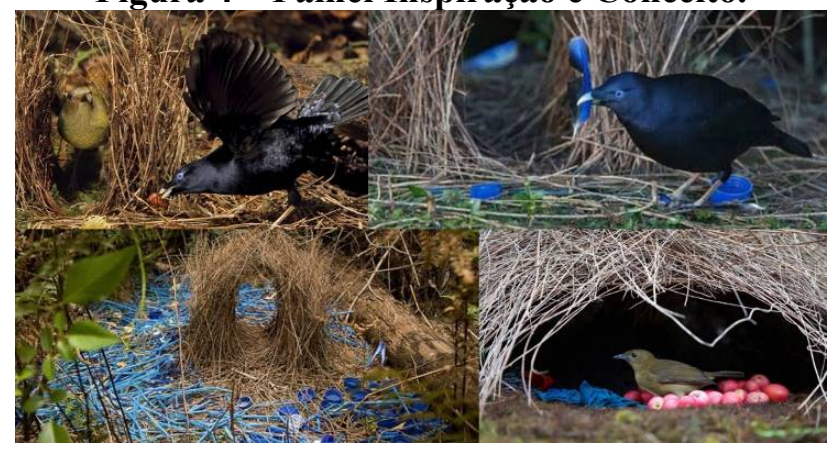

Fonte: elaborado pela autora, 2019. 
O conceito, assim, é trazer essa estética de ninho, galhos e cores para que se tornando atrativo para o público e seja ecologicamente possível a partir da utilização dos retalhos. Mesclando a responsabilidade ambiental com a relação afetiva do objeto-usuário, a pesquisadora e designer buscou alternativas para que fosse viável essa junção como forma de atribuir valor ao produto.

\subsection{Requisitos do projeto}

Segundo Pazmino (2015), o registro da necessidade como requisitos de projeto serve para facilitar no desenvolvimento do mesmo, guiando para que nenhum detalhe seja esquecido durante o processo. Os requisitos são demandas, obrigatórias ou desejáveis na implementação do projeto. Após o estudo aprofundado no público alvo, foi constatado que o Puff a ser projetado tenha como requisitos as seguintes características para satisfazer as necessidades do público alvo conforme a Figura 5.

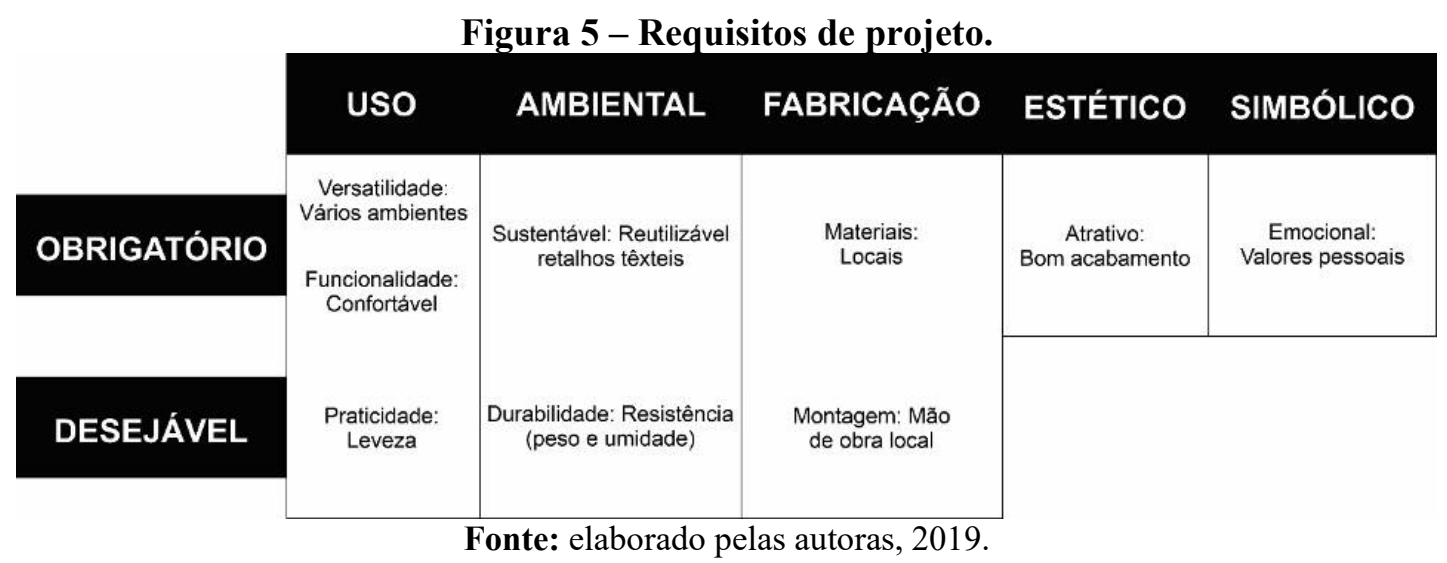

Como mostra a figura acima, o projeto é composto por requisitos desejáveis e obrigatórios. Possui cinco requisitos principais que são: de Uso, Ambiental, Fabricação, Estético e Simbólico. Os requisitos aqui expostos são de grande valia na etapa de ideação, mais especificamente na utilização da ferramenta de Matriz de Decisão e também na de Critérios de Seleção, pois ambas necessitam estar de acordo com as necessidades descritas no requisito de projeto.

\section{PuffNinho}

Muito além do objeto cadeira, da função sentar ou até mesmo da sustentabilidade com o uso dos retalhos, o PuffNinho pretende trazer ao usuário, símbolos, significados e significâncias dialogados com a subjetividade que as coisas assumem diante dos indivíduos. Mais ou menos como uma obra de arte - que despertam sentimentos e até mesmo provocam incômodos diversos - cada um dará um diferente significado a esse produto.

$\mathrm{Na}$ etapa de geração de alternativas, buscou-se sempre trazer um elemento que ativasse essa relação emocional objeto-usuário. Baseados nos requisitos do projeto, foi desenvolvido possibilidades em que os retalhos tivessem uma participação em evidência. Na Figura 6 está presente parte das Gerações de Alternativas, que tiveram a natureza e biomimética muito presentes durante essa etapa.

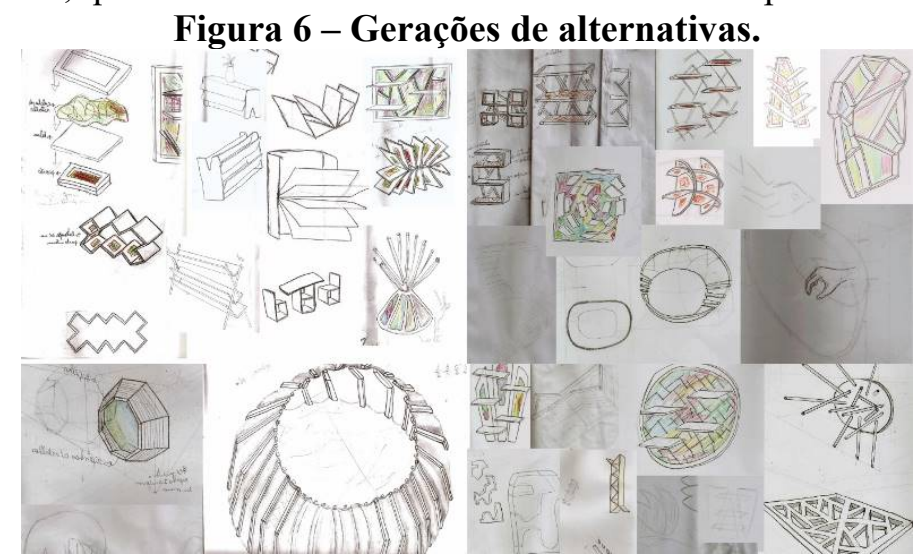

Fonte: elaborado pelas autoras, 2019. 
A partir da seleção de algumas alternativas, foi-se afunilando para aquela que mais dialogava com o projeto aqui proposto. Foi realizado alguns testes no programa SketchUp simultaneamente com fabricação de mockups para averiguação das proporções.

De acordo com Panero e Zelnik (2002) as dimensões antropométricas fundamentais para um projeto de assento buscando o bem-estar do usuário, a altura máxima em proporções que abrange homens e mulheres, é de $44,5 \mathrm{~cm}$. No mercado a grande maioria dos puffs tem a altura de $45 \mathrm{~cm}$. Para se ter praticidade na produção, optou-se pela altura total de $45 \mathrm{~cm}$. As dimensões do PuffNinho em largura e comprimento, também estão dentro das normas ergonômicas antropométricas, de modo que o assento tem o diâmetro de $50 \mathrm{~cm}$.

Como é possível observar na Figura 7, a estrutura do puff é feita de aço e unida por solda. É composta por duas partes principais além da pintura, sustentação e apoio. A primeira é formada por um aço de diâmetro maior para obter uma maior sustentação do peso, e o apoio se dá através da soldagem de mais 24 peças para assim configurar o conceito do ninho.

$\mathrm{O}$ assento do presente projeto se dá pelo trançado dos retalhos nos dois aros superiores do puff. A autora elegeu essa forma, ao invés do tradicional assento fixo em madeira e espuma, para instigar a pessoa a experimentar sentar na cadeira e se sentir envolvido pelo ninho. A sobra têxtil disposta em uma espécie de percinta, amarrada com nós firmes e em duas camadas, dão a garantia que o assento suportará o peso do usuário.

Nas laterais, os retalhos são dispostos também em nós e tramas (Figura 7). Com função estética e emocional, esses retalhos complementam o visual do produto para que ele realmente tenha uma aparência de ninho, utilizando do bom senso e moderação para que o PuffNinho não tenha um aspecto de artesanato amador.

Figura 7 - Processo de amarrações de tecido e testes.

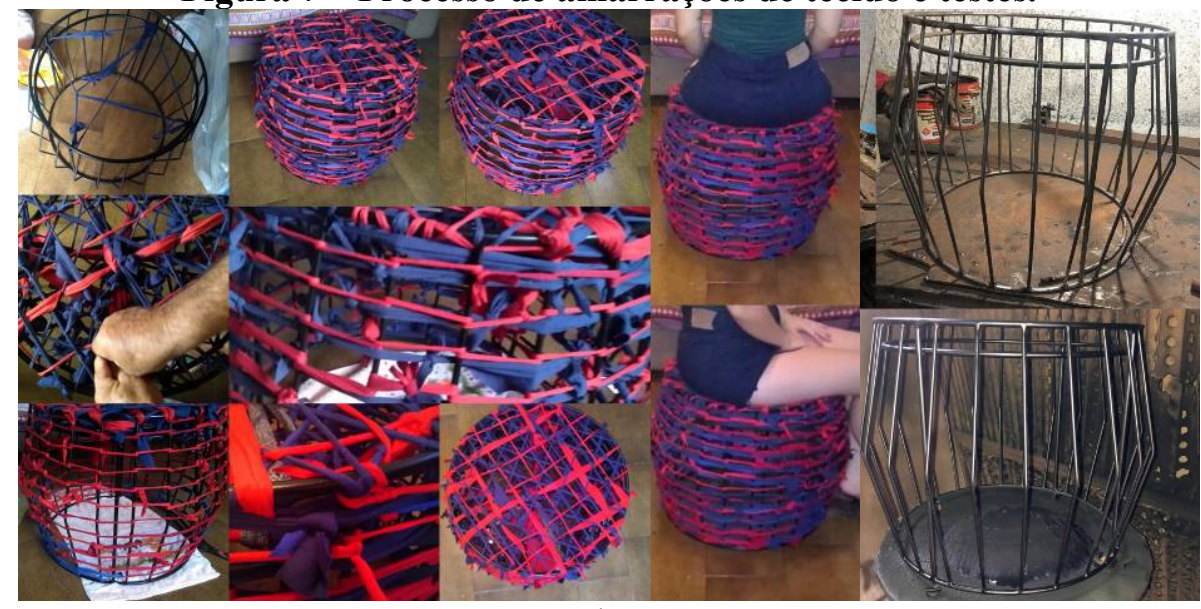

Fonte: acervo das autoras, 2019.

A escolha pela estrutura em ferro ao invés da madeira, é para se ajustar ao requisito desejável de leveza. Além de todo processo de montagem simplificar na utilização do aço trefilado, a forma fica mais limpa, harmônica e não demanda pregos ou junção por encaixes. Com um processo curto e rápido, após manusear a serra, viradeira, soldagem e pintura, a estrutura do PuffNinho já está finalizada (Figura 8). 


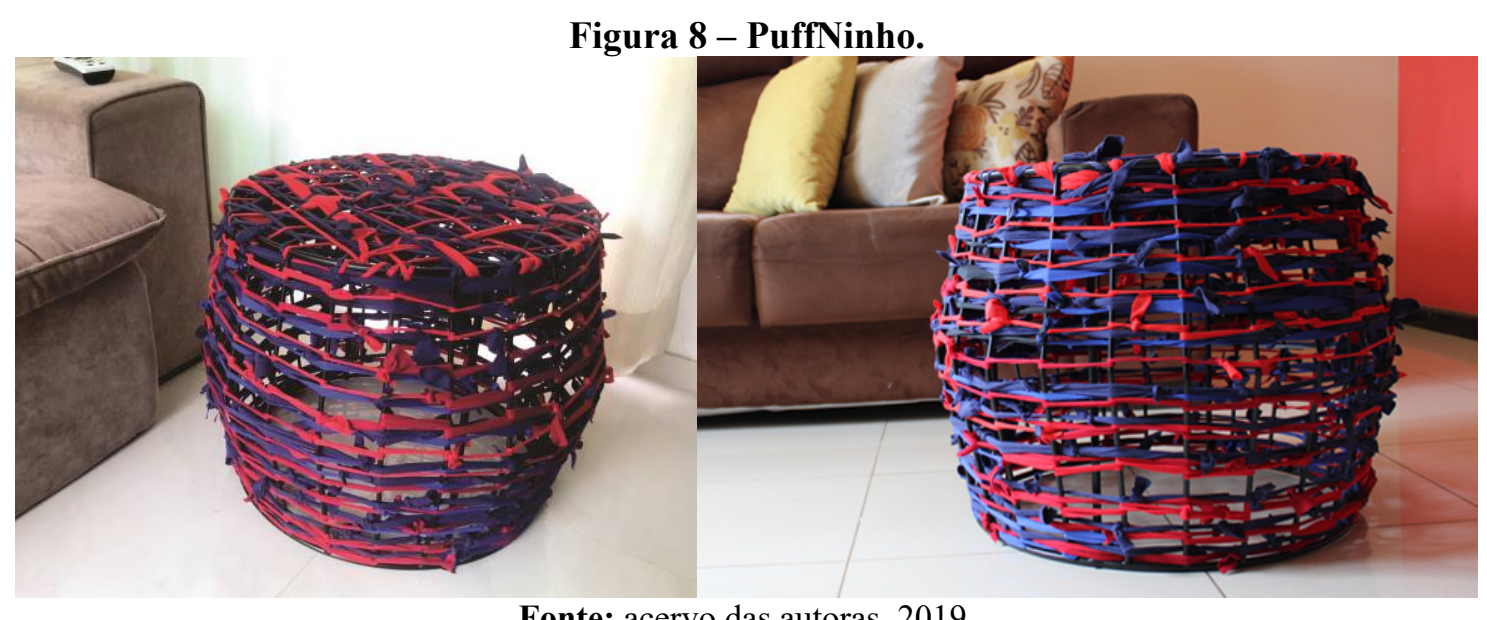

Fonte: acervo das autoras, 2019.

A configuração e disposição dos aros e arcos na estrutura, abre um leque de possibilidades para aplicação dos retalhos. Além da obtenção de um produto único em decorrência dos tipos e tamanhos variados de tecidos, as diferentes amarrações e combinações que podem ser feitas no acabamento do puff, faz com que ele proporcione diversas reações no usuário.

A oportunidade de ampliar a geração de renda local através da utilização da mão de obra e matéria prima acessíveis, dado que as técnicas artesanais de aplicação do retalho são práticas de serem ensinadas. Assim, a produção e emprego dos retalhos são aplicados de maneira efetiva, causando a diminuição dos descartes têxteis encaminhados aos lixões e aterros.

Utilizar do design como ferramenta fomentadora na criação de diálogos que convergem para a ressignificação de insumos descartados, é o que dissocia o artesanato amador do presente trabalho. A elaboração de um conceito que se relaciona diretamente com o produto final, valoriza ainda mais o significado do objeto para o comprador. O propósito de usar da estética alegre e despojada para esse público, intenciona para que gere um uma nova percepção e entendimento da possibilidade sobre as novas práticas atreladas a sustentabilidade de maneira que o móvel decorativo receba um significado além da estética. Portanto, estabelece-se um laço emocional através da experiência de uso do produto bem como os significados atrelado à ele. Gerando valor para algo que antes era desprezado, para um produto mais próximo de seu consumidor, o puff.

\section{Considerações Finais}

O têxtil está atrelado a uma das indústrias mais impactantes, a moda, que traz consigo um grande problema que é o descarte excessivo, sem planejamento prévio para o seu devido reaproveitamento. Assim, no decorrer da pesquisa foram abordados vários autores que se posicionaram e se posicionam em relação a sustentabilidade. O meio ambiente se tornou um "bem precioso" na contemporaneidade, dada à conscientização da finitude dos recursos naturais. Para tanto, existem empresas engajadas nessa causa.

O design tem um papel fundamental para transformar contextos e projetar no sentido de melhorar a qualidade de vida das pessoas, pois ele se encontra em todas as fases do desenvolvimento de um projeto, seja em pesquisa, produção, distribuição ou descarte. E uma boa estratégia sustentável, é o reaproveitamento de um material comumente sem uso, ressignificando-o para gerar valor e novas experiências de usabilidade. A partir do momento que se transforma a usabilidade de um produto ou material, estende assim, sua vida útil evitando-se o descarte precoce do mesmo.

Empregar os retalhos em um objeto consumido pelo público jovem, foi a maneira mais promissora para alcançar o objetivo de atribuir valor ao material rejeitado. Um puff coberto por nós e tramas de retalhos, de modo que o mesmo adquira personalidade e conquiste o emocional dos $\mathrm{New}$ Millennials, através da reflexão, de um novo olhar sobre o ato de se sentar e se relacionar com algo antes descartado.

Portanto, o pensamento em design agrega valor aos projetos sustentáveis, compreendendo a lógica de consumo do mercado e a demanda do público alvo, seus anseios e desejos. O design perpassa por valores indissociáveis à sociedade contemporânea a fim de privilegiar o humano. 
The reframing of textiles: how to use textile waste in creating sustainable products through design

Abstract: The research was developed in order to understand the importance of the textile industry in the world and in Brazil, about problems caused by it and how design can offer sustainable solutions from this context. The central idea of the project is an application of design in the reuse of scraps discarded by clothing, medium and large, in order to develop a product that meets sustainable thinking. Therefore, the researcher had the opportunity to research a uniform manufacturing company located in the region of the city of Ubá, in order to develop the objective of reusing the scraps discarded by the manufacture and in the future to produce a product, using design methods and tools, which resignifies the value of the tissue discarded in the current market. To this end, a study of Generation $Y$ was also carried out, identified in the research as the public of greatest interest in the topic addressed by the present project.

Keywords: sustainable design; textile; reframe; reuse

\section{Referências bibliográficas}

ABIT. Perfil do setor. Disponível em: <https://www.abit.org.br/cont/perfil-do-setor>. Acesso em 14 de mai., 2019.

ANICET, Anne. RÜTHSCHILLING, Evelise Anicet. Relações entre moda e sustentabilidade. In: Colóquio de Moda, IX., 2013, Fortaleza. Anais. Fortaleza: Universidade Federal do Ceará, 2013.Disponível em: <http://www.coloquiomoda.com.br/coloquio2017/anais/anais/edicoes/9Coloquio-de-Moda_2013/ARTIGOS-DE-GT/Artigo-GT-Moda-e-Sustentabilidade/Relacoes-entre-moda-esustentabilidade.pdf $>$.

BAXTER, M. R. Projeto de produto: guia prático para o design de novos produtos. São Paulo: Blucher, 2011.

BELCHIOR, C; RIBEIRO, R. A. da C. Estruturando uma metodologia para analisar a ressignificação como ferramenta estratégica do design. Colóquio Internacional de Design. Belo Horizonte, 2017.

CAMPANA, G. CIMATTI, B. The slow factory: a new paradigm for manufacturing. 11th Global Conference on Sustainable Manufacturing. Germany: Berlin, 2013.

DEARO, Guilherme. Existem dois tipos de millennials e eles são muito diferentes. São Paulo: Exame, 2017. Disponível em: <https://exame.com/marketing/existem-dois-tipos-millennials-muitodiferentes/>. Acesso em: 10, de ago., 2020.

DETANICO, F. B. C. TEIXEIRA, F. G. SILVA, T. K. A biomimética como método criativo para o projeto de produto. Programa de Pós-Graduação em Design da Universidade Federal do Rio Grande do Sul. Porto Alegre, 2010.SO, R. Uma introdução à história do design. São Paulo: Blucher, 2000.

G1. Pássaro caramancheiro 'cultiva' plantas para decorar seu ninho: Macho mantém o ambiente colorido para atrair as fêmeas. São Paulo: Globo Natureza, 2012. Disponível em: <http://g1.globo.com/natureza/noticia/2012/04/passaro-caramancheiro-cultiva-plantas-para-decorarseu-ninho.html>. É o primeiro registro de cultivo sem fins alimentícios no mundo animal.

IBGE. Disponível em: <https://cidades.ibge.gov.br/brasil/mg/uba/panorama>. Acesso em 16 de mai., 2019.

INTERSIND. Nosso polo. Disponível em:<http://www.intersind.com.br/nossopolo.php $>$. Acesso em 16 de mai., 2019. 
LIPOVETSKY, G. SERROY, J. A estetização do mundo: Viver na era do capitalismo artista. São Paulo: Companhia das Letras, 2015.

LUCIETTI, T. J; TRIERWEILLER, A. C; RAMOS, M. S; SORATTO, R. B. Importância do upcycling no desenvolvimento da moda: estudo de caso da marca recollection lab. Revista Internacional Interdisciplinar INTERthesis, v.15, n.2. Florianópolis, 2018.

MANZINI, EZio; VEZZOLI, Carlo. O desenvolvimento de produtos sustentáveis: os requisitos ambientais dos produtos industriais. São Paulo: EdUSP, 2008.

MENA. Isabela. Verbete draft: o que é slow design. DRAFT,2018. Disponível em: https://www.projetodraft.com/verbete-draft-o-que-e-slow-design/. Acesso em 16 de mai., 2019.

MIZUTA, E. Como o Banco de Tecido ganha dinheiro e preserva o meio ambiente eliminando o desperdício na cadeia têxtil. Disponível em: <https://projetodraft.com/como-obanco-de-tecido-ganha-dinheiro-e-preserva-o-meio-ambiente-eliminando-o-desperdicio-na-cadeiatextil/>. Acesso em: 15 de abr., 2019.

MUNARI, Bruno. Das coisas nascem coisas. Lisboa: Edições70, Lda, 1981.

NAÇÕES UNIDAS BRASIL. A ONU e o meio ambiente. Disponível em: <https://nacoesunidas.org/acao/meio-ambiente/>. Acesso em 19 de mai., 2019.

NORMAN. D. A. Design emocional: Por que adoramos (ou detestamos) os objetos do dia a dia. Rio de Janeiro: Rocco, 2008.

PANERO, J. ZELNIK, M. Dimensionamento humano para espaços interiores. Barcelona: Gustavo Gili, 2002.

PAPANEK, Victor. Arquitectura e design: ecologia e ética. Lisboa: Edições 70, 2002.

PAZMINO, Ana Verônica. Como se cria: 40 métodos para design de produtos. São Paulo: Edgard. Blucher, 2015.

PHILLIPS, P. L. Briefing: a gestão do projeto de design. São Paulo: Blucher, 2007.

RIBEIRO, R. A. da C. HORTA, A. A. COTRIM, M. de A. P. Tempo e Design: as gerações e suas lógicas de consumo. Belo Horizonte: EdUEMG, 2017.

RUTHSCHILLING, Evelise Anicet. Design de superfície. Porto Alegre: Editora UFRGS, 2008.

DETANICO, F. B. TEIXEIRA, F. G. SILVA, T. K. A biomimética como método criativo para o projeto de produto. Programa de Pós-Graduação em Design da Universidade Federal do Rio Grande do Sul. Porto Alegre, 2010.

SUDJIC, D. A linguagem das coisas. Rio de Janeiro: Intrínseca, 2010.

VIRGÍLIO, C. V. Os Millennials e a Indústria da Moda. Dissertação apresentada como requisito para aprovação no Mestrado em Branding e Design de Moda na Universidade da Beira Interior. Portugal: Covilhã, 2017.

Wanderley, Ingrid Moura; Santos, Maria Cecília Loschiavo dos; "DESIGN DOS OUTROS: UM OLHAR AOS OBJETOS COTIDIANOS (RE)CRIADOS", p. 913-925 . In: Anais do $\mathbf{1 2}^{\circ}$ Congresso Brasileiro de Pesquisa e Desenvolvimento em Design [= Blucher Design Proceedings, v. 9, n. 2]. São Paulo: Blucher, 2016. ISSN 2318-6968, DOI 10.5151/despro-ped2016-0078 ISSN 2318-6968, DOI 10.5151/despro-ped2016-0078 